\title{
Maintenance of Mouse Gustatory Terminal Field Organization Is Disrupted following Selective Removal of Peripheral Sodium Salt Taste Activity at Adulthood
}

\author{
ㅈolf Skyberg, Chengsan Sun, and David L. Hill \\ Department of Psychology, University of Virginia, Charlottesville, Virginia 22904-4400
}

Neural activity plays a critical role in the development of central circuits in sensory systems. However, the maintenance of these circuits at adulthood is usually not dependent on sensory-elicited neural activity. Recent work in the mouse gustatory system showed that selectively deleting the primary transduction channel for sodium taste, the epithelial sodium channel $(\mathrm{ENaC})$, throughout development dramatically impacted the organization of the central terminal fields of three nerves that carry taste information to the nucleus of the solitary tract. More specifically, deleting ENaCs during development prevented the normal maturation of the fields. The present study was designed to extend these findings by testing the hypothesis that the loss of sodium taste activity impacts the maintenance of the normal adult terminal field organization in male and female mice. To do this, we used an inducible Cre-dependent genetic recombination strategy to delete $\mathrm{ENaC}$ function after terminal field maturation occurred. We found that removal of sodium taste neural activity at adulthood resulted in significant reorganization of mature gustatory afferent terminal fields in the nucleus of the solitary tract. Specifically, the chorda tympani and greater superficial petrosal nerve terminal fields were $1.4 \times$ and $1.6 \times$ larger than age-matched controls, respectively. By contrast, the glossopharyngeal nerve, which is not highly sensitive to sodium taste stimulation, did not undergo terminal field reorganization. These surprising results suggest that gustatory nerve terminal fields remain plastic well into adulthood, which likely impacts central coding of taste information and taste-related behaviors with altered taste experience.

Key words: axons; medulla; neuronal activity; plasticity; taste

Significance Statement

Neural activity plays a major role in the development of sensory circuits in the mammalian brain. However, the importance of sensory-driven activity in maintaining these circuits at adulthood, especially in subcortical structures, appears to be much less. Here, we tested whether the loss of sodium taste activity in adult mice impacts the maintenance of how taste nerves project to the first central relay. We found that specific loss of sodium-elicited taste activity at adulthood produced dramatic and selective reorganization of terminal fields in the brainstem. This demonstrates, for the first time, that taste-elicited activity is necessary for the normal maintenance of central gustatory circuits at adulthood and highlights a level of plasticity not seen in other sensory system subcortical circuits.

\section{Introduction}

Neural activity plays an integral role in the proper development of sensory circuits in the CNS (Lee et al., 2005; Leake et al., 2006; Sun et al., 2017). For example, the development of mature reti-

\footnotetext{
Received Dec. 16, 2016; revised June 20, 2017; accepted June 24, 2017.

Author contributions: R.S., C.S., and D.L.H. designed research; R.S., C.S., and D.L.H. performed research;R.S., C.S., and D.L.H. analyzed data; R.S., C.S., and D.L.H. wrote the paper.

This work was supported by National Institutes of Health Grant DC00407 to D.L.H. We thank Maureen Cowan for excellent technical assistance.

The authors declare no competing financial interests.

Correspondence should be addressed to Dr. David L. Hill, Department of Psychology, PO Box 400400, University of Virginia, Charlottesville, VA 22904. E-mail: dh2t@virginia.edu.

DOI:10.1523/JNEUROSCI.3838-16.2017

Copyright $\odot 2017$ the authors $\quad 0270-6474 / 17 / 377619-12 \$ 15.00 / 0$
}

nogeniculate terminal fields into eye-specific layers in the dorsal lateral geniculate nucleus ( $\mathrm{dLGN}$ ) is dependent upon retinal ganglion cell activity early in life (Grubb et al., 2003; Pfeiffenberger et al., 2005; Hooks and Chen, 2007, 2008; Huberman et al., 2008). Similarly, the development of gustatory nerve terminal fields in the mouse nucleus of the solitary tract (NST) depends on tasteelicited neural activity. During normal development, the chorda tympani (CT), greater superficial petrosal (GSP), and glossopharyngeal nerve (IX) terminal fields are initially large and overlap extensively with each other in the NST. Then, from postnatal day 15 (P15) to P35, the CT and GSP terminal fields are "pruned" into a smaller, more segregated, mature organization (Sollars et al., 2006; Mangold and Hill, 2008; Zheng et al., 2014). Interest- 
ingly, this period of terminal field reorganization closely follows the period when epithelial sodium channel (ENaC)-mediated sodium taste stimuli become progressively more effective in driving neural responses in the CT (Hill and Bour, 1985; Zheng et al., 2014), and probably in driving neural responses in the GSP. The IX, which is not highly sodium sensitive and does not innervate taste buds with functional ENaCs (Doolin and Gilbertson, 1996; Ninomiya, 1998; Chandrashekar et al., 2010), has a terminal field that is mature by P15 (Zheng et al., 2014). Recently, Sun et al. (2017) demonstrated that the development of terminal fields was dependent on normal levels of sodium taste activity. By selectively eliminating functional ENaCs in taste buds throughout prenatal and postnatal development, the CT, GSP, and IX terminal fields in these mice were up to $2 \times$ larger than age-matched controls at adulthood.

While it is clear that neural activity is crucial for proper development of sensory circuits, it is not as clear that neural activity plays a role in maintaining circuits at adulthood. Although there is evidence that cortical sensory circuits are susceptible to changes in afferent sensory information at adulthood (Willott et al., 1993; Trachtenberg et al., 2002; Sawtell et al., 2003; Hooks and Chen, 2007), subcortical, central relays are far less plastic, or resistant, to sensory-driven alterations at adulthood (O'Leary et al., 1994; Hooks and Chen, 2007). Unlike other sensory systems, however, subcortical gustatory nuclei seem unusually plastic into adulthood. For example, functional taste responses in the NST can be modified by learning and taste experience at adulthood (Giza and Scott, 1983; Chang and Scott, 1984; Giza et al., 1997). Moreover, the anatomical terminal field organization of the rat CT reverts to the immature pattern of enlarged terminal fields when the GSP and IX are cut at adulthood (Corson and Hill, 2011). Although findings from this study suggest that a life-long plasticity exists in CT terminal fields, it did not directly test the hypothesis that taste-elicited activity maintains gustatory terminal fields at adulthood. Here, we provide a direct test of the hypothesis by selectively deleting ENaCs in adult mice. Through this method, we deleted the primary taste transduction pathway responsible for sodium taste in rodents (Heck et al., 1984; Bernstein and Hennessy, 1987; Hill et al., 1990; Spector et al., 1996; Lindemann, 2001; Chandrashekar et al., 2010; Breza and Contreras, 2012) while leaving other pathways intact that include nonsodium components of salt transduction (e.g., transduction of halogens) (Formaker and Hill, 1988; Hill et al., 1990; Lyall et al., 2004; Oka et al., 2013; Lewandowski et al., 2016). Our results show that loss of sodium taste input has profound effects on the maintenance of mature CT and GSP terminal fields. Moreover, these two terminal fields reverted to an organization resembling that seen in immature (P15) mice (Zheng et al., 2014). By contrast, the terminal field of the IX was unaffected by the removal of ENaC function in adulthood.

\section{Materials and Methods}

Animals. All experiments were approved by the University of Virginia Animal Care and Use Committee and followed guidelines set forth by the National Institutes of Health and the Society for Neuroscience. To examine the role of neural activity on the maintenance of mature gustatory terminal fields in the NST, we used an inducible Cre-dependent genetic recombination paradigm. To generate these mice, we crossed animals expressing a tamoxifen-inducible variant of Cre recombinase (CreERT2) under the control of the cytokeratin 8 (K8-CreERT2) promoter (Jackson ImmunoResearch Laboratories; 017947, RRID: IMSR_JAX:017947) with mice that were homozygous for the floxed Scnnla ( $\alpha \mathrm{ENaC})$ gene (Scnn1 $a^{\text {flox/flox }}$ ). Therefore, our experimental animals had the genotype K8-CreERT2 Scnn1 $a^{\text {flox/flox }}(\alpha \mathrm{ENaC} \mathrm{KO}, n=7 ; 4$ males/3 females). As keratin 8 (K8) is expressed in all mature taste bud cells and in the luminal epithelium of the gastrointestinal tract, these animals have the Scnn1a $(\alpha \mathrm{ENaC})$ gene removed from all these cells following tamoxifen treatments (Moll et al., 1982; Knapp et al., 1995). Dr. Edith Hummler generously gifted the Scnn $1 a^{\text {flox/flox }}$ mice to us.

The control group consisted of mice that were littermates to experimental animals but were not given tamoxifen at adulthood. This group contained animals that either expressed the CreERT2 promoter $(K 8$ CreERT2 Scnn $1 a^{\text {flox/flox }}, n=3 ; 2$ males, 1 female) or lacked the CreERT2 promoter (Scnn1a floxflox $n=5 ; 2$ males, 3 females). There were no differences between these two groups in any of the terminal field measurements; therefore, we pooled data from all 8 mice (Controls).

To confirm that tamoxifen administration was capable of inducing recombination within taste bud cells, we created a final group of mice by crossing the K8-CreERT2 mice with Cre-dependent Ai14 mice, which express a floxed tdTomato reporter (Jackson ImmunoResearch Laboratories, 007914, RRID: IMSR_JAX:00719). In these K8-CreERT2/Ai14 flox/flox mice, tamoxifen exposure induced expression of the fluorescent tdTomato reporter gene in K8-positive cells.

Tamoxifen administration. At P35, when mouse gustatory terminal fields in the NST are mature (Zheng et al., 2014), experimental animals were given tamoxifen (T5648, Sigma; mixed in corn oil, $188 \mathrm{ng} / \mathrm{g}$ body weight) to induce recombination. Tamoxifen was given via gavage Monday through Friday for 3 consecutive weeks (P35-P55). We based this exposure paradigm on previous studies that found this heavy exposure was necessary to induce recombination of genes of interest in the tongue epithelium in adults (Meng et al., 2015) and in other tissue (Ruzankina et al., 2007; McGraw et al., 2011). We also found that there was a doseresponse function relating total amount of tamoxifen to amount and length of recombination (data not shown).

To rule out off-target effects of tamoxifen administration, we gave tamoxifen (as described above) to mice lacking the CreERT2 promoter (Scnn1 $a^{\text {flox/flox }}, n=2 ; 2$ males). None of the measurements taken in these mice was different from that of control mice, suggesting that the only effects of tamoxifen in our measurements were due to the removal of the Scnnla gene.

Tissue collection. To establish that the mice used here had Scnnla removed in the tongue, we used real-time quantitative PCR (qPCR) procedures similar to that of Huang and Krimm (2010) and Sun et al. (2015).

Briefly, the anterior two-thirds of fresh tongues from $\alpha \mathrm{ENaC}$ knockout mice at 1 week after tamoxifen exposure $(n=3 ; 3$ females $)$, at 2 months after tamoxifen exposure $(n=4 ; 3$ males $/ 1$ female), and in control mice, age-matched with the 2 month post-tamoxifen groups ( $n=4 ; 1$ male/ 3 females), were collected and cut at the midline, rinsed with cold PBS, and then incubated in sterile Dispase I solution (BD Biosciences) for $60 \mathrm{~min}$ at $37^{\circ} \mathrm{C}$. Epithelial sheets of the tongue were then peeled from the underlying mesenchyme and immediately processed for RNA extraction.

RNA extraction and measurement. Total RNA was extracted using RNeasy mini kit (QIAGEN), and traces of DNA were eliminated in samples by treatment with DNase I. Total RNA was analyzed as described in detail by Sun et al. (2015).

qPCR was performed by 7500 Fast Real-Time PCR System (Applied Biosystems). Assays of $\alpha \mathrm{ENaC}$ and mouse GAPDH (catalog \#4331182, Mm00803386_m1 and Mm99999915_g1, respectively) were purchased from Thermo Fisher Scientific. PCR efficiencies were determined by performing PCR with serial (10-fold) dilutions of cDNA in parallel. All samples were run in parallel with the housekeeping gene, GAPDH, to normalize cDNA loading. Each assay was performed in triplicate. PCR was performed for $40 \mathrm{cycles}$ at $95^{\circ} \mathrm{C}$ for $15 \mathrm{~s}$ and at $60^{\circ} \mathrm{C}$ for $1 \mathrm{~min}$.

$R T-P C R$ analyses. For real-time PCR, the comparative $2^{-\Delta \Delta C T}$ method was used to determine the relative Scnn1a gene expression levels (Huang and Krimm, 2010; Sun et al., 2015).

Taste nerve neurophysiology. We recorded whole-nerve activity from the CT in our $\alpha \mathrm{ENaC} \mathrm{KO}$ and control mice ( $n=4 ; 3$ males $/ 1$ female) to ensure that Scnn 1a removal led to a selective reduction in functional taste responses from the $\mathrm{CT}$ to $\mathrm{NaCl}$, as reported previously (Sun et al., 2017). CT responses from experimental mice were tested at 1 week $(n=3$; 3 females) and 2 months $(n=4 ; 1$ male/3 females) after tamoxifen 
exposure to establish that $\mathrm{NaCl}$-elicited neural activity was reduced for the 7 week period before nerve labeling. Mice were sedated with a 0.32 $\mathrm{mg} / \mathrm{kg}$ injection of Domitor (medetomidine hydrochloride, i.m.; Pfizer Animal Health) and anesthetized with $40 \mathrm{mg} / \mathrm{kg}$ Ketaset (ketamine hydrochloride, i.m.; Fort Dodge Animal Health). A water-circulating heating pad was used to maintain body temperature. Hypoglossal nerves were transected bilaterally to prevent tongue movement, and mice were placed in a nontraumatic head holder. The left CT was isolated using a mandibular approach. The nerve was exposed near the tympanic bulla, cut, desheathed, and positioned on a platinum electrode. A second electrode was placed in nearby muscle to serve as a reference. Kwik-Sil was placed in the cavity around the nerve to keep the nerve from drying.

Stimulation procedure. All chemicals were reagent grade and prepared in artificial saliva (Hellekant et al., 1985). Neural responses from the CT were recorded to ascending concentrations series of $0.05,0.1,0.25$, and $0.5 \mathrm{M} \mathrm{NaCl}$, to 10,20 , and $50 \mathrm{~mm}$ citric acid, and finally to $0.1,0.25,0.5$, and $1.0 \mathrm{M}$ sucrose to assess the taste responses to prototypical stimuli that represent salty, sour, and sweet, respectively, to humans. (Responses to the bitter stimulus, quinine hydrochloride, were not recorded because of low response magnitudes to relatively high stimulus concentrations.) Each concentration series was bracketed by applications of $0.5 \mathrm{M} \mathrm{NH}_{4} \mathrm{Cl}$ to monitor the stability of each preparation and for normalizing taste responses. Solutions were applied to the tongue in $5 \mathrm{ml}$ aliquots with a syringe and allowed to remain on the tongue for $\sim 20 \mathrm{~s}$. We used this period of stimulation so that we could ensure enough of a period to measure steady-state responses. After each solution application, the tongue was rinsed with artificial saliva for $\geq 1 \mathrm{~min}$ (Hellekant et al., 1985). This period allowed a full recovery of neural responses (i.e., the responses were not adapted by previous responses) (Shingai and Beidler, 1985). In addition, responses were recorded to the $\mathrm{NaCl}$ concentration series in presence of the epithelial sodium channel blocker, amiloride $(50 \mu \mathrm{M})$. Rinses during this series were with amiloride in artificial saliva.

All responses were calculated as follows: the average voltage of the spontaneous activity that occurred for the second before stimulus onset was subtracted from the voltage that occurred from the period from the first to sixth second after stimulus application. Response magnitudes were then expressed as ratios relative to the mean of $0.5 \mathrm{M} \mathrm{NH}_{4} \mathrm{Cl}$ responses before and after taste stimulation. Whole-nerve response data were retained for analysis only when $0.5 \mathrm{M} \mathrm{NH}_{4} \mathrm{Cl}$ responses that bracketed a concentration series varied by $<10 \%$.

We also tested whether Scnn1a removal led to functional changes in the GSP and IX nerves by recording taste responses to a concentration series of $\mathrm{NaCl}$, sucrose, citric acid, and quinine hydrochloride $(10,20,50$, and $100 \mathrm{~mm}$ ) in two $\alpha \mathrm{ENaC} \mathrm{KO}$ (2 males) and two control (2 males) mice 2 months after tamoxifen exposure. For GSP and IX recordings, a ventral approach was taken to gain access to the GSP through the tympanic bulla and to the IX, which is located just medial to the tympanic bulla (Formaker and Hill, 1991; Sun et al., 2017). Both nerves were cut distal to the respective ganglia (GSP, geniculate ganglion; IX, petrosal ganglion), desheathed, and positioned on a platinum electrode with a second electrode in nearby muscle to serve as a reference. For both GSP and IX recordings, stimuli and rinses were delivered through tubing placed in the esophagus, allowing posterior to anterior stimulation of the entire oral cavity (Sollars and Hill, 1998). Neurophysiological taste responses from these two nerves were recorded to the same stimuli and analyzed as described for the CT.

Taste bud cell proliferation assay. Taste bud cells turnover approximately every $10 \mathrm{~d}$ in rodents (Beidler and Smallman, 1965; Farbman, 1980; Hendricks et al., 2004; Hamamichi et al., 2006; Feng et al., 2014). To ensure that tamoxifen exposure was not preventing proliferation of taste bud cells at the time of terminal field labeling, we injected mice ( $n=4$; 2 males/2 females) 2 months after tamoxifen exposure with 5-ethynyl$2^{\prime}$-deoxyuridine (EdU, $50 \mu \mathrm{g} / \mathrm{g}$ body weight, i.p.) at 4:30 P.M., 6:30 P.M., and 8:30 P.M. After $7 \mathrm{~d}$, animals were overdosed with urethane. The anterior portion of the tongue was collected, postfixed in $4 \%$ PFA for $1 \mathrm{~h}$, and then immersed in 30\% sucrose overnight. Tissue was flash frozen in isopentyl alcohol over dry ice and sectioned on a cryostat at $20 \mu \mathrm{m}$. Tissue was collected on gelatin-coated slides, placed into PBS containing $0.2 \%$ Triton for $15 \mathrm{~min}$, then washed briefly in PBS three times. Sections were then exposed to an antigen retrieval process in which they were placed into $1 \mathrm{~N} \mathrm{HCl}$ for $30 \mathrm{~min}$, followed by a brief $1 \mathrm{~min}$ immersion in $0.1 \mathrm{~m}$ borate buffer, $\mathrm{pH} 8.5$, and followed by another wash in PBS $(3 \times)$. After this, sections were placed into $10 \mathrm{~mm}$ citrate buffer, $\mathrm{pH} 8.5$, for $15 \mathrm{~min}(2 \times)$ at $80^{\circ} \mathrm{C}$. Sections were cooled and washed in PBS before being blocked with normal donkey serum for $1 \mathrm{~h}$. Tissue was then placed into PBS containing $0.2 \%$ Triton and 1:100 K8 antibody (Developmental Studies Hybridoma Bank; TROMA-1, RRID: AB_531826) overnight at $4^{\circ} \mathrm{C}$. Tissue was washed and placed in PBS containing $0.2 \%$ Triton and 1:400 donkey anti-rat 488 (Thermo Fisher Scientific; A-21208, RRID: AB_2535794) for $1 \mathrm{~h}$ to allow visualization of taste bud cells. Slides were again washed in PBS $(3 \times)$ and then placed in 1:400 AlexaFluor-555 for $1 \mathrm{~h}$ to allow visualization of Edu-positive cells (Click-it Edu Imaging Kit 555, Invitrogen). Slides were washed and coverslipped (Vectashield, Vector Laboratories).

Fluorescent anterograde nerve labeling. Procedures used to label three nerves with fluorescent tracers were the same as that described previously in mouse (Sun et al., 2015). Briefly, the CT, GSP, and the glossopharyngeal (IX) nerves were labeled with anterograde tracers to determine the volume and densities of label among their terminal fields in the NST. The CT carries taste information from taste buds in fungiform papillae on the anterior tongue and the anterior foliate papillae on the posterior tongue to the NST. The GSP carries taste information from taste buds on the soft palate, the geschmacksstreifen, and the nasoincisor duct in the palate to the NST. Finally, the IX carries taste information from taste buds in the circumvallate papilla and the posterior foliate papillae, both on the posterior tongue, to the NST (for diagram of innervation patterns, see Sun et al., 2015).

Nerve labeling was done at 4 months of age, giving a 2 month period between tamoxifen administration and nerve labeling for potential terminal field changes to occur in experimental mice. Mice were sedated with the same procedure as described in the nerve neurophysiology procedure and then placed on a water-circulating heating pad to maintain body temperature. Animals were positioned in a nontraumatic head holder (Erickson, 1966), and a ventral approach was taken to expose the GSP and CT nerves within the right tympanic bulla. The CT and GSP nerves were cut near and peripheral to the geniculate ganglion in the tympanic bulla. Crystals of $3 \mathrm{kDa}$ tetramethylrhodamine dextran amine (Thermo Fisher Scientific; D3308) were applied to the proximal cut end of the GSP and crystals of $3 \mathrm{kDa}$ biotinylated dextran amine (Thermo Fisher Scientific; D7135) were applied to the proximal cut end of the CT. The IX was isolated medial to the tympanic bulla, cut peripheral to the petrosal ganglion, and placed on a small piece of Parafilm. Crystals of $3 \mathrm{kDa}$ cascade blue dextran amine (Thermo Fisher Scientific; D7132) were applied to the proximal cut end of the IX nerve. A small amount of Kwik-Sil (World Precision Instruments) was placed over the cut ends of the nerves to prevent crystals from diffusing from the site of the intended label. Mice were then injected with $5 \mathrm{mg} / \mathrm{ml}$ Antisedan (atipamezole hydrochloride i.m.; Pfizer Animal Health) to promote reversal of anesthesia. Following $48 \mathrm{~h}$ survival, animals were deeply anesthetized with urethane and transcardially perfused with Krebs-Henseleit buffer, $\mathrm{pH}$ 7.3, followed by $4 \%$ PFA, pH 7.2.

Tissue preparation. Brains were removed, postfixed, and the medulla was blocked and sectioned horizontally on a vibratome at $50 \mu \mathrm{m}$ (Sun et al., 2015). We chose to section tissue in the horizontal plane because it allows visualization of the entire rostral-caudal and medial lateral extent of the terminal fields in the NST with the smallest number of sections $(\sim 12$ sections/mouse). It is also the plane in which the axons branch from the solitary tract and project primarily medially in rodents (Davis, 1988; Whitehead, 1988; Lasiter et al., 1989).

Sections were then incubated for $1 \mathrm{~h}$ in PBS containing $0.2 \%$ Triton with 1:400 streptavidin AlexaFluor-647 (Jackson ImmunoResearch Laboratories; 016-600-084, RRID: AB_2341101) and 1:400 rabbit antiCascade Blue (Thermo Fisher Scientific; A-5760, RRID: AB_2536192) at room temperature. Streptavidin AlexaFluor-647 was used to visualize the biotinylated dextran amine-labeled CT-positive terminals. Rabbit antiCascade Blue was used as a primary antibody to detect Cascade Bluelabeled IX terminal fields and was followed with a $1 \mathrm{~h}$ reaction with 1:400 donkey anti-rabbit AlexaFluor-488 (Thermo Fisher Scientific; A-21206, 
RRID: AB_2535792) to visualize IX nerve terminals. Tetramethylrhodamine-labeled GSP terminal fields were visualized by first incubating sections in 1:400 goat anti-Rhodamine (Vector Laboratories; SP-0602, RRID:AB_2336212) for $1 \mathrm{~h}$, followed by a $1 \mathrm{~h}$ incubation in 1:400 donkey anti-goat Cy3 (Jackson ImmunoResearch Laboratories; 705-165-147, RRID: AB_2307351). Sections were mounted on slides and coverslipped with Vectashield Hardset Mounting Medium (Vector Laboratories).

Confocal microscopy. Terminal fields were imaged using an $80 \mathrm{i}$ microscope fitted with a C2 scanning system (Nikon Instruments) and a $10 \times$ objective (Nikon, CFIPlanApo; NA = 0.45). The nerve labels were matched for the wavelengths of the three lasers in the system (argon laser, $488 \mathrm{~nm}, 10$ $\mathrm{mW}$, IX; DPSS laser, $561 \mathrm{~nm}, 10 \mathrm{~mW}$, GSP; modulated diode laser, 638 $\mathrm{nm}, 20 \mathrm{~mW}$, CT). Sequential optical sections were captured every $3 \mu \mathrm{m}$ for each $50 \mu \mathrm{m}$ section. Images were obtained with settings adjusted so that pixel intensities were near (but not at) saturation. A transmitted light image at $4 \times($ Nikon PlanFluor; NA $=0.13)$ and at $10 \times$ was captured for every physical section containing the labeled terminal field. This permitted an accurate registration of dorsal to ventral brainstem sections among animals within and between groups using common brainstem landmarks $(4 \times)$ and identification of NST borders $(10 \times)$.

Photomicrographs for figures were made from maximum intensity images of the confocal stacks of single physical sections. Only adjustments of brightness and contrast were used for images used in photomicrographs.

Analyses of total terminal field volume. Methods used to analyze terminal field volumes and densities were described previously in detail (Sun et al., 2015). Briefly, quantification of terminal field volume was achieved through the use of custom ImageJ-based software (Sun et al., 2015). Each image stack was initially rotated so that the solitary tract was oriented vertically. The border of the NST was outlined for each physical section through the use of the corresponding transmitted light image, and the stack was then cropped to include only the NST. The IsoData thresholder algorithm (Ridler and Calvard, 1978) was applied to yield a binary image stack of the labeled pixels above threshold. A particle analysis was then performed to quantify the pixel area above threshold for each channel. Specifically, the number of pixels above threshold for each optical section was summed by ImageJ, converted into area by multiplying the number of pixels by pixel size $(1.24 \mu \mathrm{m} \times 1.24 \mu \mathrm{m})$, and then multiplied by $3 \mu \mathrm{m}$ (i.e., distance between optical sections) to determine the volume of each label in each physical section. Volumes from each physical section were summed to yield the total terminal field volume for each mouse. The resultant volume represents an unbiased experimenter measure of the amount of label. Additionally, the volume of colocalization between the terminal fields of two nerves (CT with GSP, GSP with IX, CT with IX) and among all three nerves (CT, GSP, and IX) was determined in a similar manner as described for each single label.

Axons (e.g., the solitary tract) were included along with the terminal field for all animals in our analyses because of the difficulty in accurately deleting axons and tracts from each optical section. Accordingly, the absolute volumes that we show here include the composite terminal field and axons. There was no obvious reorganization of nerve tracts among groups; therefore, we make the assumption that including the solitary tract in our measurements had a similar quantitative effect among groups.

Analyses of terminal field volume of labels in dorsal-ventral zones. The analyses of terminal field volumes here are the same as was done to study the role of sodium salt-elicited taste responses on the development of IX, CT, and GSP terminal fields in mice (Sun et al., 2017). We examined the volume of labeled terminal fields in four dorsal-ventral zones. Each zone was defined by brainstem landmarks in horizontal sections (for details, see Sun et al., 2015). The landmarks in controls and $\alpha \mathrm{ENaC}$ knock-out mice were similar to that that described by Sun et al. (2015).

Examination of terminal fields in coronal sections. The NST from 2 $\alpha \mathrm{ENaC} \mathrm{KO}$ and 2 control mice were sectioned coronally on a vibratome at $50 \mu \mathrm{m}$ and imaged as described above. Coronal sections were used to examine the extent of terminal field expansion and overlapping fields in the NST. No quantitative measurements were taken. Coronal sections were also imaged with transmitted light following confocal microscopy of the fluorescently labeled terminal fields to allow visualization of labeled terminal fields in coronal sections.

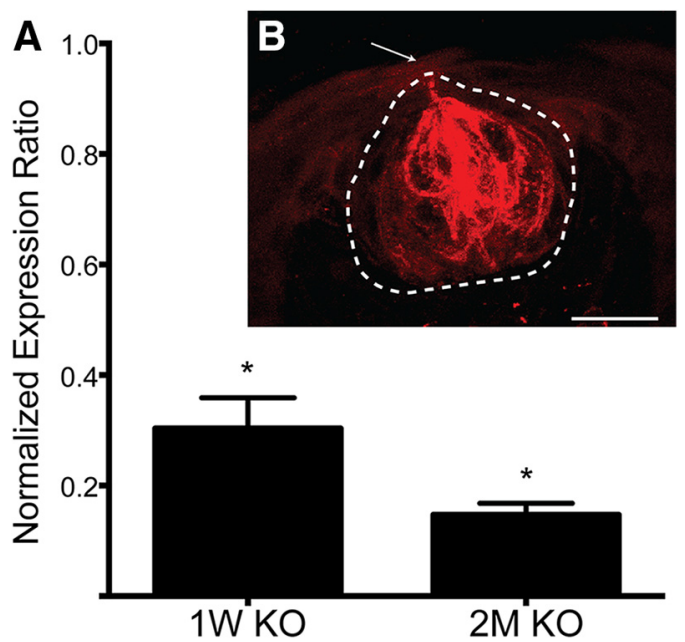

Figure 1. Tamoxifen is capable of regulating gene expression within K8 taste bud cells $\boldsymbol{A}$, Mean ( \pm SEM) normalized expression levels of $\alpha E N a C$ in the anterior tongue of $\alpha \mathrm{ENaC} \mathrm{KO}$ mice 1 week and 2 months after tamoxifen exposure. Means were calculated relative to the respective expression levels in control mice. The expression ratio of 1.0 represents the control mean. $\boldsymbol{B}$, Photomicrograph showing a coronal section of a taste bud taken at $40 \times$ from a K8-CreERT2-Ai14 ${ }^{\text {flox/flox }}$ mouse 2 months after tamoxifen exposure. Tamoxifen administration successfully induced expression of tdTomato (red) in taste bud cells through the 2 month period following tamoxifen exposure. Dotted line indicates the taste bud border. Arrow indicates the taste bud pore. ${ }^{*} p<0.05$. Scale bar: $B, 50 \mu \mathrm{m}$.

Experimental design and statistical analysis: terminal field volumes. The mean $( \pm$ SEM) was calculated for the total CT, GSP, and IX nerve terminal field volumes, for their overlapping field volumes, and for terminal field volumes within the four, defined dorsal-ventral zones. We first analyzed the terminal fields by comparing volumes among the three nerves (i.e., IX, CT, GSP). We then separately analyzed terminal fields by comparing the overlaps among the nerves (e.g., CT with GSP). This was done through a two-way ANOVA (SPSS, ANOVA; experimental group $\times$ nerve/overlap), with post hoc pairwise comparisons done with Bonferroni post-tests (SPSS, RRID: SCR_002865). For all statistical tests, we considered $p$ values $\leq 0.05$ to be significant.

Amount of $\alpha E N a C$ expression in taste buds following tamoxifen treatment. The amount of $\alpha E N a C$ expression in $\alpha \mathrm{ENaC} \mathrm{KO}$ mice at 1 week and 2 months after tamoxifen injection was analyzed with a one-way ANOVA (SPSS).

Number of sections labeled with anterograde tracers. We used an unpaired $t$ test to compare the number of physical brain sections containing nerve label between groups.

Functional taste responses from the chorda tympani nerve. A two-way repeated-measures ANOVA (SPSS) was used to compare mean ( \pm SEM) relative CT responses (compared with $0.5 \mathrm{M} \mathrm{NH}_{4} \mathrm{Cl}$ responses) between control and $\alpha \mathrm{ENaC} \mathrm{KO}$ mice 2 months after tamoxifen to a concentration series of $\mathrm{NaCl}$, sucrose, and citric acid ( 2 groups $\times 3$ or 4 concentrations; post hoc pairwise comparisons done with Bonferroni post-tests). The same analysis was also done between $\alpha \mathrm{ENaC} \mathrm{KO}$ mice at 1 week and 2 months after tamoxifen.

\section{Results}

Tamoxifen administration induces recombination and reduces $\alpha \mathrm{ENaC}$ expression in taste buds

We found, through qPCR, that expression of the Scnnla gene in the tongue epithelium of $\alpha \mathrm{ENaC} \mathrm{KO}$ was reduced to $30.3 \%$ of controls 1 week after tamoxifen exposure and further reduced to $14.7 \%$ by 2 months after drug administration (Fig. $1 A$; Table 1; post-tests, $p=0.04$ for both comparisons). Thus, 3 weeks of tamoxifen treatment was sufficient to significantly reduce expression of the Scnnla gene for the duration of the 7 week period before terminal field data were collected. 
Table 1. ANOVA results ${ }^{a}$

\begin{tabular}{llrrl}
\hline Measure & Factor & df & \multicolumn{1}{l}{ F } & Significance \\
\hline qPCR for ENaC in tongue & Tamoxifen treatment & 2,6 & 177.0 & 0.00001 \\
$\mathrm{NaCl}$ taste response & Group & 1,6 & 47.8 & 0.0001 \\
$\mathrm{NaCl}$ taste response & Group $\times$ concentration & 3,18 & 14.2 & 0.0001 \\
$\mathrm{NaCl}$ after amiloride & Group & 1,5 & 0.4 & 0.85 \\
$\mathrm{NaCl}$ after amiloride & Group $\times$ concentration & 3,15 & 0.9 & 0.45 \\
Citric acid taste response & Group & 1,6 & 0.3 & 0.59 \\
Citric acid taste response & Group $\times$ concentration & 2,12 & 4.4 & 0.06 \\
Sucrose taste response & Group & 1,6 & 1.0 & 0.36 \\
Sucrose taste response & Group $\times$ concentration & 3,18 & 0.2 & 0.98 \\
Total volume-single nerves & Group & 1,39 & 29.9 & 0.0001 \\
Total volume-single nerves & Group $\times$ nerve & 2,39 & 4.1 & 0.02 \\
Total volume- overlap & Group & 1,52 & 2.4 & 0.13 \\
Total volume- overlap & Group $\times$ nerve & 3,52 & 1.4 & 0.23 \\
Far dorsal volume-single nerves & Group & 1,39 & 2.4 & 0.13 \\
Far dorsal volume-single nerves & Group $\times$ nerve & 2,39 & 0.1 & 0.89 \\
Far dorsal volume- overlap & Group & 1,52 & 2.4 & 0.13 \\
Far dorsal volume- overlap & Group $\times$ nerve & 3,52 & 0.1 & 0.99 \\
Dorsal volume-single nerves & Group & 1,39 & 14.0 & 0.001 \\
Dorsal volume-single nerves & Group $\times$ nerve & 2,39 & 1.8 & 0.19 \\
Dorsal volume- overlap & Group & 1,52 & 2.2 & 0.15 \\
Dorsal volume- overlap & Group $\times$ nerve & 3,52 & 1.7 & 0.91 \\
Intermediate volume-single nerves & Group & 1,39 & 18.5 & 0.0001 \\
Intermediate volume-single nerves & Group $\times$ nerve & 2,39 & 5.6 & 0.007 \\
Intermediate volume- overlap & Group & 1,52 & 0.0 & 0.96 \\
Intermediate volume- overlap & Group $\times$ nerve & 3,52 & 1.9 & 0.15 \\
Ventral volume-single nerves & Group & 1,39 & 0.9 & 0.36 \\
Ventral volume-single nerves & Group $\times$ nerve & 2,39 & 0.7 & 0.49 \\
Ventral volume- overlap & Group & 1,52 & 10.9 & 0.002 \\
Ventral volume- overlap & Group $\times$ nerve & 3,52 & 0.3 & 0.99 \\
\hline & & &
\end{tabular}

${ }^{a}$ Measures appear in the order presented in Results.

Figure $1 B$ shows an optical section of a coronal section through the center of a taste bud from a K8-CreERT2 Ai14 flox/flox mouse 2 months after tamoxifen administration. Recombination within the lingual epithelium (assessed by the presence of tdTomato) was limited to taste bud cells. These data show the specificity of our K8 promoter in the oral epithelium and provides evidence that recombination in taste bud cells occurred for up to 2 months after tamoxifen administration. Similar to what we found here, Meng et al. (2015) also reported that tamoxifen was sufficient in inducing recombination in taste buds up to 10 weeks after drug exposure. Furthermore, they found that the period following tamoxifen exposure was correlated to the amount of tamoxifen injected: larger injections led to longer periods of recombination.

\section{$\alpha \mathrm{ENaC} \mathrm{KO}$ animals have diminished whole-nerve CT and GSP responses to $\mathrm{NaCl}$}

To confirm that tamoxifen-induced recombination resulted in a decrease in ENaC-mediated taste responses, we first compared whole-nerve recordings from the $\mathrm{CT}$ of control and $\alpha \mathrm{ENaC} \mathrm{KO}$ mice. We chose to record taste responses from the CT because the cellular population it innervates in the periphery should be highly affected by the experimental manipulation (Chandrashekar et al., 2010). Again, we tested CT responses 1 week and 2 months after tamoxifen exposure in our experimental mice.

Removal of the Scnn1a gene from K8-positive cells in adult $\alpha \mathrm{ENaC} \mathrm{KO}$ had large effects on taste responses in the CT to $\mathrm{NaCl}$. In control mice, progressively increasing $\mathrm{NaCl}$ stimulus concentrations elicited corresponding increases in taste response magnitudes to $\mathrm{NaCl}$ (Fig. 2A), and this increase was significantly attenuated after lingual application of amiloride (Fig. 2B). By contrast, the relative $\mathrm{NaCl}$ responses seen in $\alpha \mathrm{ENaC} \mathrm{KO}$ mice were significantly diminished across all concentrations before amiloride application (Fig. 2C), and amiloride had little suppressive effects on the $\mathrm{NaCl}$ response in $\alpha \mathrm{ENaC} \mathrm{KO}$ mice (Fig. $2 D$ ). The inability of amiloride in attenuating $\alpha \mathrm{ENaC} \mathrm{KO}$ nerve responses to $\mathrm{NaCl}$ provides evidence that $\mathrm{ENaCs}$ did not participate in transduction of sodium-salt taste stimuli in $\alpha \mathrm{ENaC} \mathrm{KO}$ mice. Figure $2 E$ shows that relative taste responses of the CT to the concentration series of $\mathrm{NaCl}$ in $\alpha \mathrm{ENaC} \mathrm{KO}$ mice were significantly lower than in controls for all concentrations of $\mathrm{NaCl}$, except for $0.05 \mathrm{M} \mathrm{NaCl}$ (Fig. $2 E$; Table 1 ; significant post-tests, $p=$ 0.003-0.0001). Importantly, $\mathrm{NaCl}$-driven CT responses, before and after amiloride, from $\alpha \mathrm{ENaC} \mathrm{KO}$ mice at 1 week and 2 months after tamoxifen exposure were not significantly different from each other (Fig. 2E). Thus, these functional data establish that tamoxifen administration was sufficient to highly attenuate taste responses to $\mathrm{NaCl}$ for the 7 weeks before the three nerves were labeled.

By contrast to data shown for $\mathrm{NaCl}$ responses, $\mathrm{CT}$ responses to a concentration series of citric acid and sucrose were unaffected by removal of the Scnn1a gene (data not shown). For citric acid, the main effect for group and the group $\times$ concentration interaction was not significant (Table 1). Similarly, the main effect for group and the group $\times$ concentration interaction was not significant for sucrose (Table 1). These results are similar to what has been previously reported by Chandrashekar et al. (2010) and Sun et al. (2017).

We also examined taste responses in the GSP and in the IX in 2 control and $2 \alpha \mathrm{ENaC} \mathrm{KO}$ mice to test whether inducibly deleting ENaCs from taste buds at adulthood also had an effect on taste responses. Figure 2 shows integrated responses from the GSP before (F) and after (G) amiloride application in a control mouse. As seen earlier by Sun et al. (2017), the GSP in controls is highly responsive to a concentration series of $\mathrm{NaCl}$; and these responses, especially at lower concentrations, are sensitive to amiloride. By contrast, the GSP in $\alpha \mathrm{ENaC} \mathrm{KO}$ mice is poorly responsive to low concentrations of $\mathrm{NaCl}$ before amiloride (Fig. $2 \mathrm{H}$ ) and showed no increase in response magnitudes after $0.25 \mathrm{M}$ $\mathrm{NaCl}$. Application of amiloride had no effect on the $\mathrm{NaCl}$ response in the GSP in $\alpha \mathrm{ENaC} \mathrm{KO}$ mice (Fig. 2J), which is similar to what was found for the CT (Fig. $2 E$ ). We note here that the slope of the integrated response to $0.5 \mathrm{M} \mathrm{NH}_{4} \mathrm{Cl}$ is much sharper in this recording than in others, which makes measuring the steady-state response magnitude more difficult to determine.

In contrast to the other two nerves, the IX was much less responsive to $\mathrm{NaCl}$ in controls, especially to lower concentrations of $\mathrm{NaCl}$ (Fig. $2 \mathrm{~K}$ ). Moreover, the relative response magnitudes of the IX were unchanged when amiloride was applied to controls (Fig. 2L). Importantly, removal of ENaCs from taste buds had no effect on the relative responses in $\alpha \mathrm{ENaC} \mathrm{KO}$ mice compared with controls for $\mathrm{NaCl}$ responses before and after amiloride application (Fig. 2M-O). As noted for the CT, response magnitudes from the GSP and the IX to a concentration series of sucrose, citric acid, and quinine were similar between $\alpha \mathrm{ENaC} \mathrm{KO}$ mice and controls (data not shown).

\section{Tamoxifen does not prevent taste bud cell proliferation}

We found that the neurophysiological deficits induced by tamoxifen administration persist for at least 7 weeks. This was surprising because taste bud cells are a regenerative population that are replaced approximately every $10 \mathrm{~d}$ (Beidler and Smallman, 1965; Farbman, 1980; Hendricks et al., 2004; Hamamichi et al., 2006; Feng et al., 2014); therefore, these taste bud cells should regain 


\section{Before Amiloride After Amiloride}

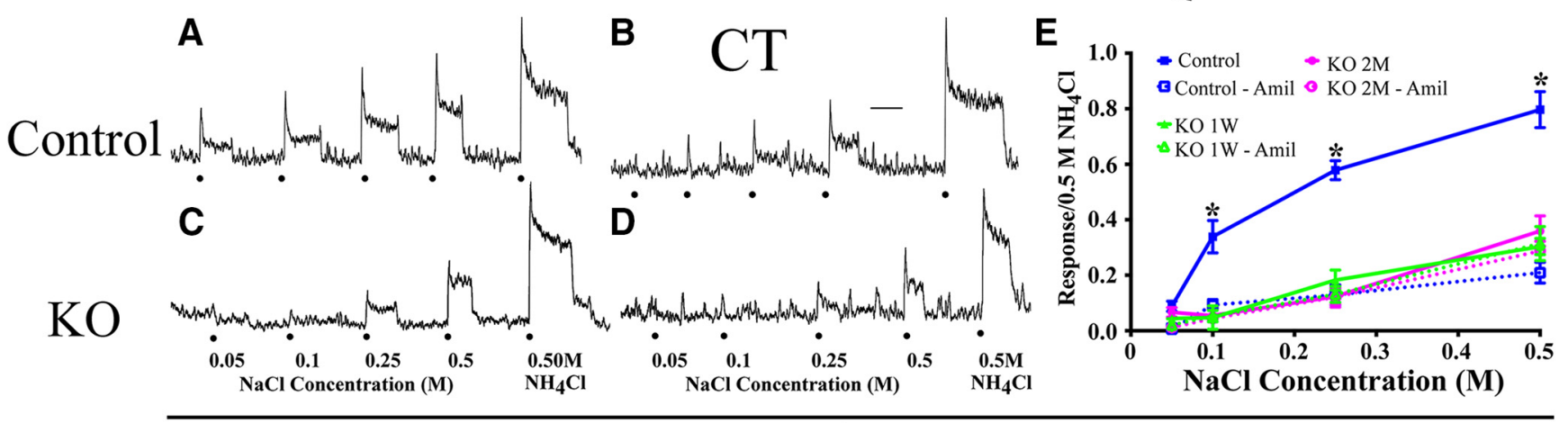

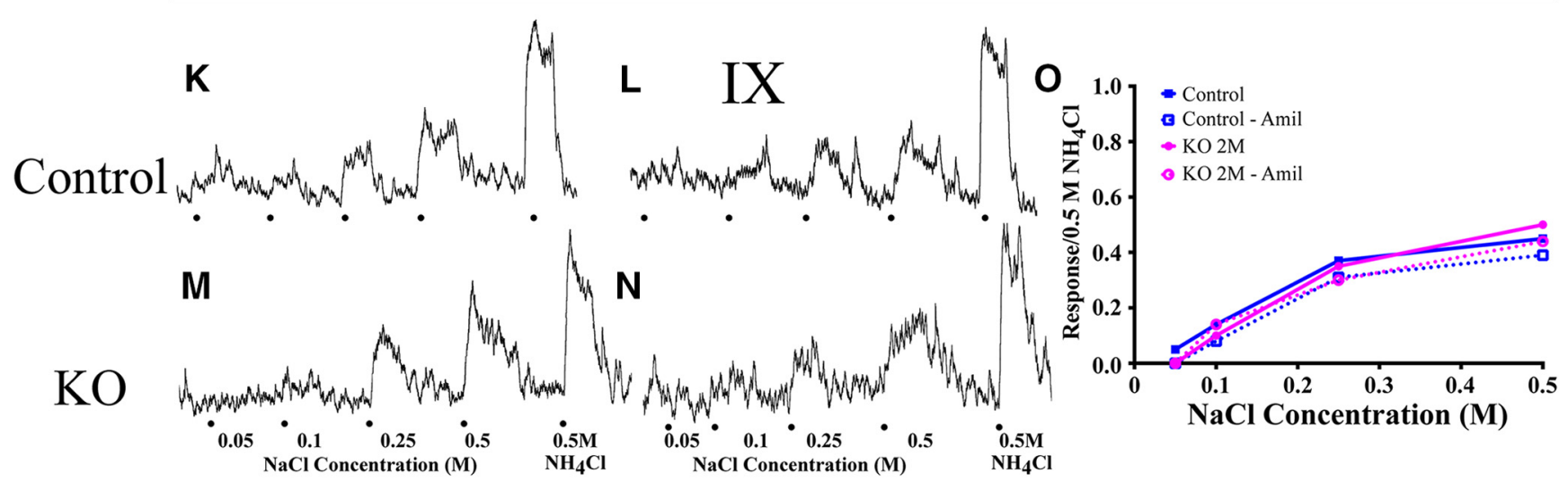

Figure 2. Integrated whole-nerve taste responses from the $C T(\boldsymbol{A}-\boldsymbol{D}), \operatorname{GSP}(\boldsymbol{F}-\boldsymbol{I})$, and $\mathrm{IX}(\boldsymbol{K}-\boldsymbol{N})$ in control $(\boldsymbol{A}, \boldsymbol{B}, \boldsymbol{F}, \boldsymbol{G}, \boldsymbol{K}, \boldsymbol{L})$ and $\alpha \mathrm{ENaCKO}(\boldsymbol{C}, \boldsymbol{D}, \boldsymbol{H}, \boldsymbol{I}, \boldsymbol{M}, \boldsymbol{N})$ mice to an increasing concentration series of $\mathrm{NaCl}(0.05,0.1,0.25$, and $0.5 \mathrm{M})$ and to $0.5 \mathrm{M} \mathrm{NH}_{4} \mathrm{Cl}$. Responses were recorded before $(\boldsymbol{A}, \boldsymbol{C}, \boldsymbol{F}, \boldsymbol{H}, \boldsymbol{K}, \boldsymbol{M})$ and after $(\boldsymbol{B}, \boldsymbol{D}, \boldsymbol{G}, \boldsymbol{I}, \boldsymbol{L}, \boldsymbol{N})$ lingual application of the ENaC blocker, amiloride. Dots indicate stimulus presentation. Calibration: $\boldsymbol{B}, 20$ s. Quantification of whole-nerve NaCl responses from the CT (E), GSP $(\boldsymbol{J})$, and IX (0) before (solid lines) and after amiloride (dotted lines). Responses were calculated as the response to each stimulus expressed relative to the $0.5 \mathrm{M} \mathrm{NH}_{4}(\mathrm{Cl}$ response. $\boldsymbol{E}$, Mean ( $\pm \mathrm{SEM}$ ) CT responses from control (blue, $n=4), \alpha \mathrm{ENaC} \mathrm{KO}$ mice 1 week after (green, $n=3$ ), and 2 months after tamoxifen treatment (magenta, $n=4)$. ${ }^{*} p<0.05$. GSP $(J)$ and IX ( $(0)$ responses were recorded in a control (blue, $n=1$ ) and an $\alpha$ ENaC KO mouse 2 months after tamoxifen treatment (magenta, $n=1$ ).

normal function well before 2 months after tamoxifen administration. We were concerned that tamoxifen arrested taste bud cell proliferation. Figure 3 shows a coronally sectioned taste bud from an $\alpha \mathrm{ENaC}$ KO mouse exposed to EdU 2 months after tamoxifen treatment. The presence of EdU-positive labeled cells and colocalization with the taste bud cell label, TROMA-1, illustrates that tamoxifen is indeed not arresting the proliferative cycle in taste bud cells.

In summary, 3 consecutive weeks of tamoxifen exposure removes functional $\mathrm{ENaCs}$ for up to 7 weeks, which in turn has major functional effects on sodium taste responses in the CT and GSP. However, removal of ENaCs does not affect neural activity driven by nonsodium salt stimuli, does not affect taste responses from the IX, and does not affect turnover of taste bud cells.

$\alpha \mathrm{ENaC} \mathrm{KO}$ mice have selectively larger terminal fields in the NST

The removal of functional ENaCs at adulthood had a significant effect on the total volume of terminal field labeling of two of the three gustatory nerves and on their overlapping fields compared with controls (Fig. 4). Specifically, the total mean terminal field size of the GSP and CT terminal fields and their overlapping field were $1.7 \times, 1.5 \times$, and $1.4 \times$ larger than the respective control vol- 


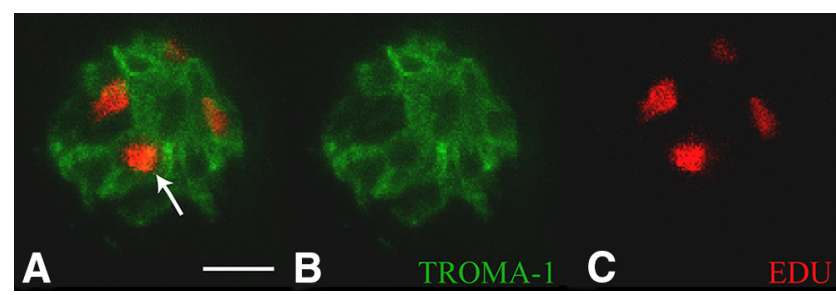

Figure 3. Photomicrograph showing a coronal section of a taste bud imaged at $60 \times$, 2 months after tamoxifen exposure. $\boldsymbol{A}$, Merged image showing K8 antibody labeling (TROMA-1; green) and anti-Edu labeling (red). White arrow indicates an EdU-positive cell within the taste bud. $\boldsymbol{B}$, TROMA-1 immunofluorescence alone. $\boldsymbol{C}$, EdU immunofluorescence alone. Scale bar: A, $10 \mu \mathrm{m}$.

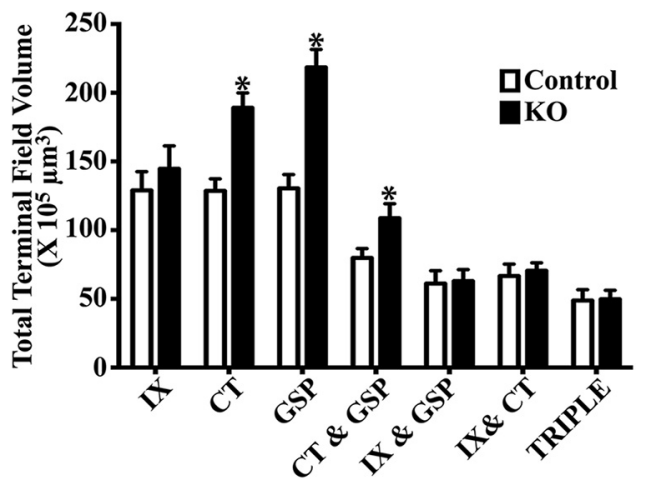

Figure 4. Mean ( \pm SEM) total terminal field volumes of the terminal field for the $I X, C T$, and GSP nerves and their double and triple overlaps of terminal fields in control mice (open bars, $n=8$ ) and KO mice (closed bars, $n=7$ ). ${ }^{*} p<0.05$.

umes (Fig. 4; Table 1; significant post-tests, $p=0.0001, p=0.001$, and $p=0.02$ for GSP, CT, and CT with GSP overlap, respectively). These terminal field differences were not trivial: 1.7 -fold and 1.5-fold increases for the GSP and CT represent an increase of $88.1 \times 10^{5} \mu \mathrm{m}^{3}$ and a $60.5 \times 10^{5} \mu \mathrm{m}^{3}$ of total terminal field volumes, respectively. Moreover, the range of terminal field volumes for the control CT and GSP did not overlap with the respective range in $\alpha \mathrm{ENaC} \mathrm{KO}$ mice (CT range: control, $85-155 \times 10^{5}$

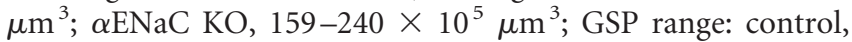
$\left.88-160 \times 10^{5} \mu \mathrm{m}^{3} ; \alpha \mathrm{ENaC} \mathrm{KO}, 179-287 \times 10^{5} \mu \mathrm{m}^{3}\right)$. By contrast, the mean terminal field volume of the IX in $\alpha \mathrm{ENaC} \mathrm{KO}$ mice was only $12 \%$ greater than in controls $(p>0.05$; Fig. 4$)$, and only one animal in each group was outside of the IX terminal field range of the other group (IX range: control, 55-175 $\times 10^{5} \mu \mathrm{m}^{3}$; $\alpha \mathrm{ENaC} \mathrm{KO}, 100-224 \times 10^{5} \mu^{3}$ ). Finally, the mean ( \pm SEM) number of $50 \mu \mathrm{m}$ sections containing any labeling in $\alpha \mathrm{ENaC}$ KO mice (12.2 \pm 1.9$)$ was not significantly different from controls $\left(11.5 \pm 1.9 ; \mathrm{t}_{(13)}=0.65, p=0.52\right)$, indicating that the projections did not extend beyond the normal dorsal-ventral extent of label in the NST in $\alpha \mathrm{ENaC} \mathrm{KO}$ mice.

Despite significant increases in both GSP and CT individual terminal fields and in the CT with GSP overlapping field in $\alpha \mathrm{ENaC} \mathrm{KO}$ mice, the mean total terminal field overlap for the other double terminal field overlaps and for the triple overlap were not significantly different from that in controls $(p>0.05$; Fig. 4).

The group-related differences in terminal field volume occur in two of the four dorsal-ventral zones

To further examine group-related differences in terminal field volumes of the three nerves and their overlapping fields, we com- pared means of terminal field volumes between controls and $\alpha \mathrm{ENaC} \mathrm{KO}$ mice within far dorsal, dorsal, intermediate, and ventral zones, as described by Sun et al. (2015).

\section{Far dorsal zone}

The far dorsal zone of the gustatory terminal field is characterized in controls by more of the NST occupied by IX label than CT and GSP labels. By contrast, nearly the same amounts of label were found for the IX, CT, and GSP in $\alpha \mathrm{ENaC} \mathrm{KO}$ mice (Fig. $5 A, B$ ). Although there appears to be more GSP in $\alpha \mathrm{ENaC} \mathrm{KO}$ mice, there were no significant group-related differences in the mean amount of label for any of the nerves (Fig. 5B; Table 1). Similarly, none of the overlapping terminal fields in $\alpha \mathrm{ENaC} \mathrm{KO}$ mice was significantly different from that in controls (Fig. 5B; Table 1).

\section{Dorsal zone}

This zone is characterized in controls by robust labeling of all nerves and similar amounts and shapes of terminal fields for the IX, GSP, and CT. By comparison, there was more GSP and CT than IX labeling in $\alpha \mathrm{ENaC} \mathrm{KO}$ mice (Fig. $5 C, D$ ), which resulted in larger GSP and CT fields in $\alpha \mathrm{ENaC} \mathrm{KO}$ mice compared with control mice (Table 1; post-test, $p=0.002$ and $p=0.02$ for GSP and CT, respectively). Specifically, the GSP and CT were $116 \%$ and $78 \%$ greater, respectively, in $\alpha \mathrm{ENaC} \mathrm{KO}$ mice compared with controls. There were also relatively large amounts of terminal field overlaps among all overlapping terminal fields for both groups (Fig. 5C,D), illustrating how they share similar territory in the NST. However, there were no group-related differences between groups for any double or triple terminal field overlaps (Fig. 5D; Table 1).

\section{Intermediate zone}

Of all zones analyzed, the intermediate zone contained the most terminal field labeling in both groups of mice. In controls, the IX, GSP, and CT all had similarly sized terminal fields in this region of the NST. However, the GSP and CT terminal fields in this region were larger than the IX in $\alpha \mathrm{ENaC} \mathrm{KO}$ mice, and were $1.7 \times$ and $1.5 \times$ larger, respectively, than they were in controls (Fig. $5 E, F$; Table 1; post-test, $p=0.0005$ and $p=0.0023$ for GSP and $\mathrm{CT}$, respectively). Moreover, this is the only zone in which one of the overlapping fields was greater in $\alpha \mathrm{ENaC} \mathrm{KO}$ mice compared with controls. The CT with GSP overlapping field was $1.4 \times$ greater in $\alpha \mathrm{ENaC} \mathrm{KO}$ mice compared with controls (Fig. $5 F$; Table 1; post-test, $p=0.04$;).

\section{Ventral zone}

In controls, this zone had relatively small amounts of IX terminal field label and more focused GSP and CT terminal label than in more dorsal zones (Fig. 5G,H). In $\alpha \mathrm{ENaC} \mathrm{KO}$ mice, there appeared to be less IX terminal field label than in controls, although the means were not significantly different from each other (Fig. $5 H$; Table 1). The GSP and CT labels also appeared more diffuse than in controls, but the mean terminal field volumes were similar between groups (Fig. $5 H ; p>0.05$ ). Even though the main effect of group was significant (Table 1 ), the group $\times$ nerve interaction was not significant (Fig. 5G,H; Table 1 ) and none of the post-tests was significant.

\section{Examination of terminal field density in the four dorsal-ventral zones}

In our study of the effects of deletion of $\alpha \mathrm{ENaC}$ on the development of terminal field organization (Sun et al., 2017), we qualitatively examined the terminal field densities of the three nerves 

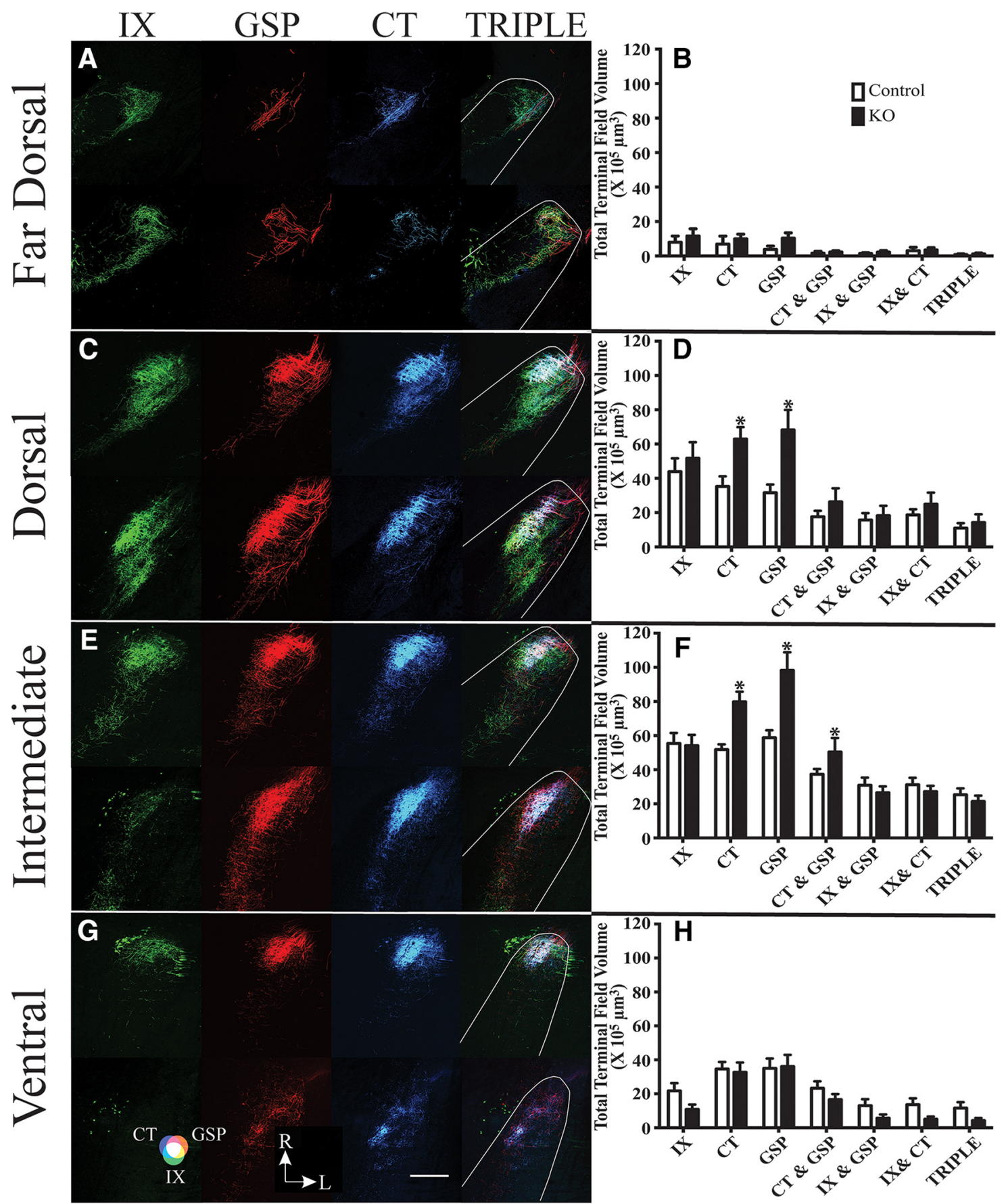

Figure 5. Horizontal sections of labeled terminal fields of IX (green), GSP (red), CT (blue), and merged images of all three nerves (TRIPLE) for control (top row of each panel) and $\alpha \mathrm{ENaC}$ KO mice (bottom row of each panel) mice in the far dorsal $(\boldsymbol{A})$, dorsal $(\boldsymbol{C})$, intermediate $(\boldsymbol{E})$, and ventral $(\boldsymbol{G})$ zones within the mouse NST. Magenta represents the (T-GSP overlap. Yellow represents the IX-GSP overlap. Blue-green represents the IX-CT overlap. White represents the CT-GSP-IXterminal field overlap. G, Color guide. Scale bar: G, $200 \mu \mathrm{m}$. R, Rostral; L, lateral shown in G. Mean ( \pm SEM) terminal field volumes of $\mathrm{IX}, \mathrm{CT}$, and GSP nerves and their overlapping fields in the far dorsal $(\boldsymbol{B})$, dorsal (D), intermediate $(\boldsymbol{F})$, and ventral $(\boldsymbol{H})$ zones in control (open bars) and K0 (filled bars) mice. Asterisks shown for terminal field volumes indicate a significant difference between controls and $\alpha \mathrm{ENaC} \mathrm{KO}$ mice $(p<0.05)$.

and their triple overlapping fields within each of the four dorsalventral zones. This allowed us to test whether the terminal fields were arranged differently along the $x-y$ axis in knock-out mice. Briefly, we found that the density and spread of the terminal fields for all nerves were greater in mice when $\alpha \mathrm{ENaC}$ was deleted early in development compared with controls. We did the same qualitative examination here; and unlike our earlier study, we found no systematic differences between groups and among nerves. That is, the densest regions of terminations did not occur solely in $\alpha \mathrm{ENaC} \mathrm{KO}$ mice, and similarly, a largest spread of label in the NST was not always in the experimental group.

Coronal sections show similar terminal field changes in $\alpha \mathrm{ENaC}$ KO mice

Figure 6 shows the terminal fields of each gustatory nerve as well as their triple overlap in the coronal plane. These sections are representative of terminal fields located in the rostral portion of the NST. Specifically, these coronal sections were $\sim 450 \mu \mathrm{m}$ from 


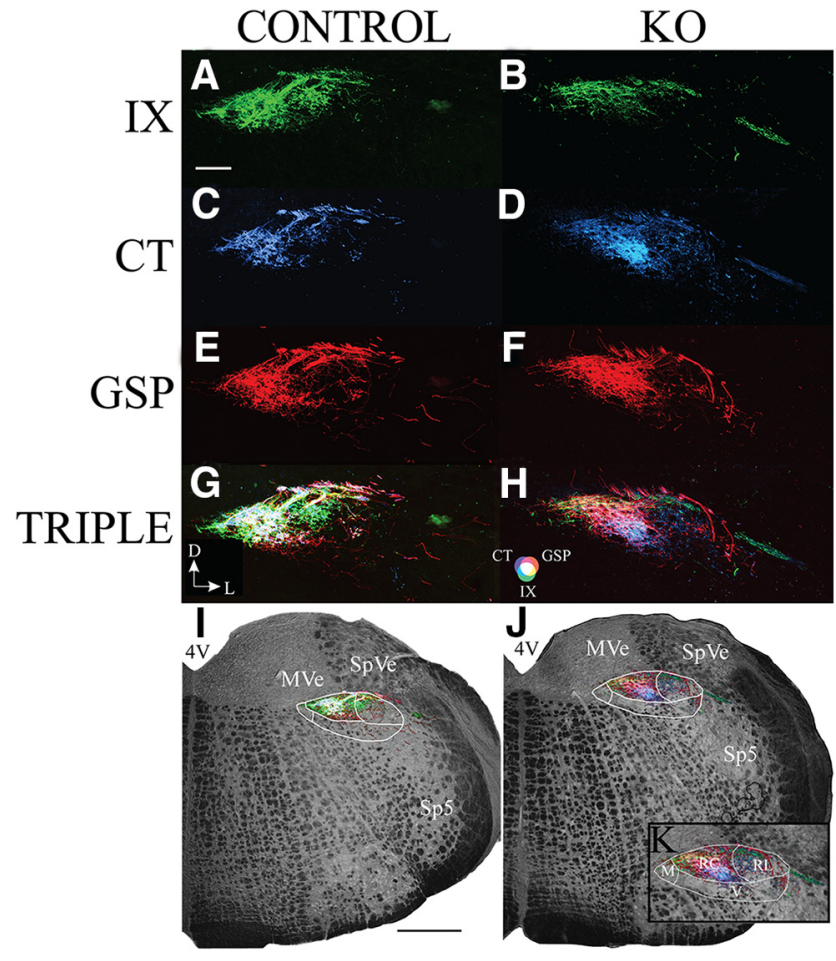

Figure 6. Coronal sections through the rostral NST showing the IX (green; $A, B$ ), CT (blue; $\boldsymbol{C}, \boldsymbol{D})$, and GSP (red; $\boldsymbol{E}, \boldsymbol{F})$ terminal fields, TRIPLE terminal fields $(\boldsymbol{G}, \boldsymbol{H})$, and the terminal fields in the right hemifield overlaid on the medulla captured with transmitted light $(I, J)$ in control $(\boldsymbol{A}, \boldsymbol{C}, \boldsymbol{E}, \boldsymbol{G}, \boldsymbol{I})$ and $\alpha \mathrm{ENaC} \mathrm{KO}(\boldsymbol{B}, \boldsymbol{D}, \boldsymbol{F}, \boldsymbol{H}, \boldsymbol{J}, \boldsymbol{K})$ mice. $\mathbf{G}$, Orientation of the sections. D, Dorsal; L, lateral. Magenta represents the CT-GSP overlap. Yellow represents the IX-GSP overlap. Bluegreen represents the IX-CT overlap. White represents the CT-GSP-IX terminal field overlap. $\boldsymbol{H}$, Color guide. $\boldsymbol{I}, \boldsymbol{J}$, White outer outlines approximately demarcate the NST. Lines within the outlines indicate NST subdivisions. $\boldsymbol{K}$, Enlarged view of the terminal fields in $\boldsymbol{J}$ to illustrate the subdivisions of the NST. M, Medial subdivision; RC, rostrocentral subdivision; RL, rostrolateral subdivision; $V$, ventral subdivision. Scale bars: $A, 200 \mu \mathrm{m} ; I, 500 \mu \mathrm{m}$. 4V, Fourth ventricle; Sp5, spinal trigeminal nucleus; SpVe, spinal vestibular nucleus; MVe, medial vestibular nucleus; $7 \mathrm{~N}$, facial nucleus.

the rostral-most pole of the NST. Because the NST is angled ventrally from the caudal to rostral extents, these coronal sections best represent intermediate horizontal sections of the NST described earlier. Previous studies in rat and mice showed that all three afferent gustatory terminal fields terminate primarily in the rostral-central subdivision and, to a lesser extent, in the rostrallateral subdivision (Corson et al., 2012; Ganchrow et al., 2014). Consistent with what we found in the analysis of horizontal sections through the NST, there was qualitatively an overall increase in the amount of label associated with both GSP and CT but not IX (Fig. 6). Both the GSP and CT terminal fields extended more laterally in $\alpha \mathrm{ENaC} \mathrm{KO}$ animals than in controls, and almost all of the increase in label of these terminal fields was contained within the rostral-central subdivision of the NST and less so in the rostral-lateral subdivision (for a detailed description of the coronal subdivisions of the NST, see Corson et al., 2012; Ganchrow et al., 2014).

\section{Discussion}

Reduction of taste-elicited neural activity via removal of $\alpha \mathrm{ENaC}$ in mouse taste buds at adulthood resulted in a significant reorganization of the mature CT and GSP terminal fields in the rostral NST. Interestingly, the IX terminal field was not affected. The magnitude and specificity of the terminal field changes we see at the first central relay in adults are unlike similar circuits involving sensory nerve inputs into the brain in other sensory systems.

We propose that this nerve-related specificity of effect is due to a difference in the taste-elicited activity carried by each of the three nerves. The most effective taste stimulus for the GSP and CT in rodents is $\mathrm{NaCl}$ (Hill and Bour, 1985; Sollars and Hill, 1998; Sun et al., 2017). Moreover, these responses in both nerves can be highly attenuated by the ENaC blocker, amiloride (Hill and Bour, 1985; Sollars and Hill, 1998; Sun et al., 2017) (Fig. 2A-J). In contrast, the IX is poorly sensitive to $\mathrm{NaCl}$, even at high concentrations, and the responses are not amiloride-sensitive (Formaker and Hill, 1991; Doolin and Gilbertson, 1996; Ninomiya, 1998) (Fig. $2 \mathrm{~K}-\mathrm{O}$ ). Together, these data suggest that our inducible genetic manipulation to reduce sodium taste-elicited neural activity should only affect the GSP and CT terminal fields, but not the IX field. This hypothesis is consistent with the results we report here.

\section{Role of neural activity in NST terminal field development and maintenance}

Previous research shows that removal of ENaC-mediated neural activity, beginning embryonically, prevents normal terminal field development, leading to CT, GSP, and IX terminal fields that are up to $2 \times$ larger than controls (Sun et al., 2017). Consistent with this, we show that a similar genetic manipulation in adult mice leads to an expansion of CT and GSP terminal field volumes by $\sim 1.6 \times$. Moreover, the terminal field changes were primarily restricted to specific dorsal-ventral zones in the NST, in both embryonic and adult $\alpha \mathrm{ENaC} \mathrm{KO}$ groups (Sun et al., 2017). Therefore, it appears as though both the normal "pruning" of the CT and GSP terminal fields during development and the maintenance of CT and GSP terminal fields at adulthood may be dependent on ENaC-mediated neural activity. More specifically, at adulthood, the appearance of CT and GSP terminal fields reverts to an immature organization (Zheng et al., 2014), becoming diffusely distributed without this neural activity. This return to an immature terminal field pattern has been reported in other studies on gustatory terminal field development and plasticity and suggested to be the default organization in the absence of neural activity and synaptic competition (May and Hill, 2006; Corson and Hill, 2011; Sun et al., 2017). It appears, however, that a threshold of duration and/or magnitude of altered taste-elicited activity is necessary to alter terminal field organization at adulthood. Decreasing sodium-driven activity in the CT of adult rats for $9 \mathrm{~d}$ through a low-sodium diet (Garcia et al., 2008) is ineffective in altering CT terminal field size (Krimm and Hill, 1997).

Interestingly, removal of sodium taste activity during development or at adulthood had differential effects on the IX terminal field. Although removal of ENaC-mediated activity, beginning embryonically, resulted in enlarged IX terminal fields at adulthood, the same manipulation had no effect on the size of the IX terminal field when begun at adulthood. Given that IX is not highly sensitive to $\mathrm{NaCl}$ stimulation (Fig. $2 \mathrm{~K}-\mathrm{O}$ ) and its terminal field size does not change throughout normal mouse development (Zheng et al., 2014), one would predict that reduced sodium taste responses should not have an effect on the IX field. This prediction holds for the $\alpha \mathrm{ENaC} \mathrm{KO}$ mice used here, but not for mice where $\alpha \mathrm{ENaC}$ is knocked out before birth. Thus, our findings suggest that at least two different mechanisms are at work that shape terminal fields in these two groups of $\alpha \mathrm{ENaC} \mathrm{KO}$ mice. We propose, among many possibilities, that the reduced neural activity in mice with $\alpha \mathrm{ENaC}$ knocked out during embryonic development leads to local changes in the NST, which in turn affects the developing organization of the IX terminal field. 
These processes may include early alterations in the developmental expression of growth factors (Menna et al., 2003; Sun et al., 2015), or processes involved in "pruning" of excess synapses, similar to that identified in the developing retinogeniculate system (Schafer et al., 2012). Although it is equally unclear what mechanisms are responsible for the altered terminal field changes at adulthood, one potential candidate involves alterations in the level of BDNF in the NST. Release of BDNF is activity-dependent and facilitates synaptic survival and stability (Hu et al., 2005; Kuczewski et al., 2009). We recently found that removal of BDNF from all cells, including from taste nerves and from NST neurons, results in large-scale increases in all gustatory terminal field volumes (Sun et al., 2015). Significantly decreasing the amount of taste-elicited activity (e.g., sodium taste) in the CT and GSP at adulthood may have similar effects on the maintenance of these two terminal fields by reducing the amount of released BDNF. Similarly, normal taste-elicited activity in the IX of $\alpha \mathrm{ENaC}$ knock-out mice should release sufficient amounts of BDNF to maintain its terminal field organization at adulthood. Regardless of the specific mechanism(s), both the BDNF removal study and the present study illustrate the remarkable amount of plasticity retained into adulthood by this system.

\section{Comparisons with primary afferent nerve circuits in other sensory systems}

In the retinogeniculate pathway, spontaneous neural activity (i.e., retinal waves) is required for normal development of retinogeniculate terminals within the dLGN during early postnatal ages (Chapman, 2000; Grubb et al., 2003; Pfeiffenberger et al., 2005; Demas et al., 2006; Hooks and Chen, 2007, 2008; Huberman et al., 2008). However, given that retinal waves are only present for a relatively early period of development (Wong, 1999; Muir-Robinson et al., 2002) after which visually evoked activity becomes more prevalent, the role of retinal waves in terminal field maintenance does not appear to persist into adulthood. Additionally, while visually evoked activity promotes strengthening of retinogeniculate synapses through $\sim 4$ postnatal weeks (Hooks and Chen, 2006, 2008), it has not been shown to be necessary for the maintenance of retinogeniculate terminal fields at adulthood. Similarly, trigeminal terminal fields in the principal nucleus in the brainstem require neural activity for only a brief early critical period to develop properly (O'Leary et al., 1994; Lee et al., 2005). Trigeminal nerve axons organize into barrelettes, which are topographically and functionally related to the location of vibrissae on the face. Disruption of NMDA receptor-mediated neural activity before the appearance of barrelettes prevents their maturation, suggesting that neuronal activity is required for the proper refinement of these terminal fields (Lee et al., 2005). Peripheral alterations after the critical period have little to no effect on somatosensory organization (Woolsey, 1990). Finally, the tonotopic organization of the auditory nerve terminal field in the brainstem is susceptible to changes brought about by altered neural activity. Adult cats deafened as neonates by ototoxic drug administration show a less specific topographic organization of auditory fibers in the cochlear nucleus compared with cats with functional hearing in adulthood (Leake et al., 2006). However, a role for sensory activity in the maintenance of mature auditory terminals has not been found (Rubel and Fritzsch, 2002; Kandler et al., 2009). In summary, most primary afferent sensory nerves share a dependence upon neural activity to develop mature projections at the first central relay and a degree of limited synaptic plasticity may extend into older ages. By comparison, we now show that the gustatory system requires neural activity for termi- nal field development and for terminal field maintenance into adulthood. Future experiments that alter afferent taste activity other than to sodium may provide evidence if the ENaC-driven activity altered here is necessary for GSP and CT terminal field maintenance or if the effects are merely due to an overall decrease in neural activity.

The differences in adult plasticity within these systems are likely manifestations of differences in anatomy, physiology, and/or function. For example, in the gustatory system, taste bud cells turn over every $\sim 10 \mathrm{~d}$ throughout the animal's life (Beidler and Smallman, 1965; Farbman, 1980; Hendricks et al., 2004; Hamamichi et al., 2006; Feng et al., 2014), which results in everchanging receptive fields throughout the animal's life. These are the same neurons that exhibit lifelong plasticity in their receptive fields in taste buds (i.e., peripheral and central limbs of the same neurons, respectively). None of these characteristics is present in the visual, auditory, or trigeminal systems. If a goal of primary afferent neurons is to reliably relay sensory information from the periphery to the CNS, and the peripheral organization is constantly changing, then one might expect the plasticity in the CNS to reflect the peripheral changes. Accordingly, the large changes in terminal field organization that we see here likely impact physiological changes in how taste-related information converges onto postsynaptic partners, thereby influencing sensory coding of taste, and behavioral consequences related to feeding and motivated behaviors (Spector and Travers, 2005; Spector and Glendinning, 2009).

\section{References}

Beidler LM, Smallman RL (1965) Renewal of cells within taste buds. J Cell Biol 27:263-272. CrossRef Medline

Bernstein IL, Hennessy CJ (1987) Amiloride-sensitive sodium channels and expression of sodium appetite in rats. Am J Physiol 253:R371-R374. Medline

Breza JM, Contreras RJ (2012) Anion size modulates salt taste in rats. J Neurophysiol 107:1632-1648. CrossRef Medline

Chandrashekar J, Kuhn C, Oka Y, Yarmolinsky DA, Hummler E, Ryba NJ, Zuker CS (2010) The cells and peripheral representation of sodium taste in mice. Nature 464:297-301. CrossRef Medline

Chang FC, Scott TR (1984) Conditioned taste aversions modify neural responses in the rat nucleus tractus solitarius. J Neurosci 4:1850-1862. Medline

Chapman B (2000) Necessity for afferent activity to maintain eye-specific segregation in ferret lateral geniculate nucleus. Science 287:2479-2482. CrossRef Medline

Corson J, Aldridge A, Wilmoth K, Erisir A (2012) A survey of oral cavity afferents to the rat nucleus tractus solitarii. J Comp Neurol 520:495-527. CrossRef Medline

Corson SL, Hill DL (2011) Chorda tympani nerve terminal field maturation and maintenance is severely altered following changes to gustatory nerve input to the nucleus of the solitary tract. J Neurosci 31:7591-7603. CrossRef Medline

Davis BJ (1988) Computer-generated rotation analyses reveal a key threedimensional feature of the nucleus of the solitary tract. Brain Res Bull 20:545-548. CrossRef Medline

Demas J, Sagdullaev BT, Green E, Jaubert-Miazza L, McCall MA, Gregg RG, Wong RO, Guido W (2006) Failure to maintain eye-specific segregation in nob, a mutant with abnormally patterned retinal activity. Neuron 50: 247-259. CrossRef Medline

Doolin RE, Gilbertson TA (1996) Distribution and characterization of functional amiloride-sensitive sodium channels in rat tongue. J Gen Physiol 107:545-554. CrossRef Medline

Erickson RP (1966) Nontraumatic headholder for rats. Physiol Behav 1:9798. CrossRef

Farbman AI (1980) Renewal of taste bud cells in rat circumvallate papillae. Cell Tissue Kinet 13:349-357. Medline

Feng P, Huang L, Wang H (2014) Taste bud homeostasis in health, disease, and aging. Chem Senses 39:3-16. CrossRef Medline 
Formaker BK, Hill DL (1988) An analysis of residual $\mathrm{NaCl}$ taste response after amiloride. Am J Physiol 255:R1002-R1007. Medline

Formaker BK, Hill DL (1991) Lack of amiloride sensitivity in SHR and WKY glossopharyngeal taste responses to NaCl. Physiol Behav 50:765-769. CrossRef Medline

Ganchrow D, Ganchrow JR, Cicchini V, Bartel DL, Kaufman D, Girard D, Whitehead MC (2014) Nucleus of the solitary tract in the C57BL/6J mouse: subnuclear parcellation, chorda tympani nerve projections, and brainstem connections. J Comp Neurol 522:1565-1596. CrossRef Medline

Garcia JM, Curtis KS, Contreras RJ (2008) Behavioral and electrophysiological taste responses change after brief or prolonged dietary sodium deprivation. Am J Physiol Regul Integr Comp Physiol 295:R1754-R1761. CrossRef Medline

Giza BK, Scott TR (1983) Blood glucose selectively affects taste-evoked activity in rat nucleus tractus solitarius. Physiol Behav 31:643-650. Medline

Giza BK, Ackroff K, McCaughey SA, Sclafani A, Scott TR (1997) Preference conditioning alters taste responses in the nucleus of the solitary tract of the rat. Am J Physiol 273:R1230-R1240. Medline

Grubb MS, Rossi FM, Changeux JP, Thompson ID (2003) Abnormal functional organization in the dorsal lateral geniculate nucleus of mice lacking the beta 2 subunit of the nicotinic acetylcholine receptor. Neuron 40: 1161-1172. CrossRef Medline

Hamamichi R, Asano-Miyoshi M, Emori Y (2006) Taste bud contains both short-lived and long-lived cell populations. Neuroscience 141:21292138. CrossRef Medline

Heck GL, Mierson S, DeSimone JA (1984) Salt taste transduction occurs through an amiloride-sensitive sodium transport pathway. Science 223: 403-405. CrossRef Medline

Hellekant G, af Segerstad CH, Roberts T, van der Wel H, Brouwer JN, Glaser D, Haynes R, Eichberg JW (1985) Effects of gymnemic acid on the chorda tympani proper nerve responses to sweet, sour, salty and bitter taste stimuli in the chimpanzee. Acta Physiol Scand 124:399-408. CrossRef Medline

Hendricks SJ, Brunjes PC, Hill DL (2004) Taste bud cell dynamics during normal and sodium-restricted development. J Comp Neurol 472:173182. CrossRef Medline

Hill DL, Bour TC (1985) Addition of functional amiloride-sensitive components to the receptor membrane: a possible mechanism for altered taste responses during development. Brain Res 352:310-313. Medline

Hill DL, Formaker BK, White KS (1990) Perceptual characteristics of the amiloride-suppressed sodium chloride taste response in the rat. Behav Neurosci 104:734-741. CrossRef Medline

Hooks BM, Chen C (2006) Distinct roles for spontaneous and visual activity in remodeling of the retinogeniculate synapse. Neuron 52:281-291. CrossRef Medline

Hooks BM, Chen C (2007) Critical periods in the visual system: changing views for a model of experience-dependent plasticity. Neuron 56:312326. CrossRef Medline

Hooks BM, Chen C (2008) Vision triggers an experience-dependent sensitive period at the retinogeniculate synapse. J Neurosci 28:4807-4817. CrossRef Medline

Hu B, Nikolakopoulou AM, Cohen-Cory S (2005) BDNF stabilizes synapses and maintains the structural complexity of optic axons in vivo. Development 132:4285-4298. CrossRef Medline

Huang T, Krimm RF (2010) Developmental expression of Bdnf, Ntf4/5, and TrkB in the mouse peripheral taste system. Dev Dyn 239:2637-2646. CrossRef Medline

Huberman AD, Feller MB, Chapman B (2008) Mechanisms underlying development of visual maps and receptive fields. Annu Rev Neurosci 31: 479-509. CrossRef Medline

Kandler K, Clause A, Noh J (2009) Tonotopic reorganization of developing auditory brainstem circuits. Nat Neurosci 12:711-717. CrossRef Medline

Knapp L, Lawton A, Oakley B, Wong L, Zhang C (1995) Keratins as markers of differentiated taste cells of the rat. Differentiation 58:341-349. CrossRef

Krimm RF, Hill DL (1997) Early prenatal critical period for chorda tympani nerve terminal field development. J Comp Neurol 378:254-264. CrossRef Medline

Kuczewski N, Porcher C, Lessmann V, Medina I, Gaiarsa JL (2009) Activitydependent dendritic release of BDNF and biological consequences. Mol Neurobiol 39:37-49. CrossRef Medline

Lasiter PS, Wong DM, Kachele DL (1989) Postnatal development of the rostral solitary nucleus in rat: dendritic morphology and mitochondrial enzyme activity. Brain Res Bull 22:313-321. CrossRef Medline

Leake PA, Hradek GT, Chair L, Snyder RL (2006) Neonatal deafness results in degraded topographic specificity of auditory nerve projections to the cochlear nucleus in cats. J Comp Neurol 497:13-31. CrossRef Medline

Lee LJ, Lo FS, Erzurumlu RS (2005) NMDA receptor-dependent regulation of axonal and dendritic branching. J Neurosci 25:2304-2311. CrossRef Medline

Lewandowski BC, Sukumaran SK, Margolskee RF, Bachmanov AA (2016) Amiloride-insensitive salt taste is mediated by two populations of type III taste cells with distinct transduction mechanisms. J Neurosci 36:19421953. CrossRef Medline

Lindemann B (2001) Receptors and transduction in taste. Nature 413:219225. CrossRef Medline

Lyall V, Heck GL, Vinnikova AK, Ghosh S, Phan TH, Alam RI, Russell OF, Malik SA, Bigbee JW, DeSimone JA (2004) The mammalian amilorideinsensitive non-specific salt taste receptor is a vanilloid receptor- 1 variant. J Physiol 558:147-159. CrossRef Medline

Mangold JE, Hill DL (2008) Postnatal reorganization of primary afferent terminal fields in the rat gustatory brainstem is determined by prenatal dietary history. J Comp Neurol 509:594-607. CrossRef Medline

May OL, Hill DL (2006) Gustatory terminal field organization and developmental plasticity in the nucleus of the solitary tract revealed through triple-fluorescence labeling. J Comp Neurol 497:658-669. CrossRef Medline

McGraw CM, Samaco RC, Zoghbi HY (2011) Adult neural function requires MeCP2. Science 333:186. CrossRef Medline

Meng L, Ohman-Gault L, Ma L, Krimm RF (2015) Taste bud-derived BDNF is required to maintain normal amounts of innervation to adult taste buds. eNeuro 2:ENEURO.0097-15.2015. CrossRef Medline

Menna E, Cenni MC, Naska S, Maffei L (2003) The anterogradely transported BDNF promotes retinal axon remodeling during eye specific segregation within the LGN. Mol Cell Neurosci 24:972-983. CrossRef Medline

Moll R, Franke WW, Schiller DL, Geiger B, Krepler R (1982) The catalog of human cytokeratins: patterns of expression in normal epithelia, tumors and cultured cells. Cell 31:11-24. CrossRef Medline

Muir-Robinson G, Hwang BJ, Feller MB (2002) Retinogeniculate axons undergo eye-specific segregation in the absence of eye-specific layers. J Neurosci 22:5259-5264. Medline

Ninomiya Y (1998) Reinnervation of cross-regenerated gustatory nerve fibers into amiloride-sensitive and amiloride-insensitive taste receptor cells. Proc Natl Acad Sci U S A 95:5347-5350. CrossRef Medline

Oka Y, Butnaru M, von Buchholtz L, Ryba NJ, Zuker CS (2013) High salt recruits aversive taste pathways. Nature 494:472-475. CrossRef Medline

O'Leary DD, Ruff NL, Dyck RH (1994) Development, critical period plasticity, and adult reorganizations of mammalian somatosensory systems. Curr Opin Neurobiol 4:535-544. CrossRef Medline

Pfeiffenberger C, Cutforth T, Woods G, Yamada J, Rentería RC, Copenhagen DR, Flanagan JG, Feldheim DA (2005) Ephrin-As and neural activity are required for eye-specific patterning during retinogeniculate mapping. Nat Neurosci 8:1022-1027. CrossRef Medline

Ridler TW, Calvard S (1978) Picture thresholding using an iterative selection method. IEEE T Syst Man Cyb 8:630-632. CrossRef

Rubel EW, Fritzsch B (2002) Auditory system development: primary auditory neurons and their targets. Annu Rev Neurosci 25:51-101. CrossRef Medline

Ruzankina Y, Pinzon-Guzman C, Asare A, Ong T, Pontano L, Cotsarelis G, Zediak VP, Velez M, Bhandoola A, Brown EJ (2007) Deletion of the developmentally essential gene ATR in adult mice leads to age-related phenotypes and stem cell loss. Cell Stem Cell 1:113-126. CrossRef Medline

Sawtell NB, Frenkel MY, Philpot BD, Nakazawa K, Tonegawa S, Bear MF (2003) NMDA receptor-dependent ocular dominance plasticity in adult visual cortex. Neuron 38:977-985. CrossRef Medline

Schafer DP, Lehrman EK, Kautzman AG, Koyama R, Mardinly AR, Yamasaki R, Ransohoff RM, Greenberg ME, Barres BA, Stevens B (2012) Microglia sculpt postnatal neural circuits in an activity and complementdependent manner. Neuron 74:691-705. CrossRef Medline

Shingai T, Beidler LM (1985) Response characteristics of three taste nerves in mice. Brain Res 335:245-249. CrossRef Medline

Sollars SI, Hill DL (1998) Taste responses in the greater superficial petrosal nerve: substantial sodium salt and amiloride sensitivities demonstrated in two rat strains. Behav Neurosci 112:991-1000. CrossRef Medline

Sollars SI, Walker BR, Thaw AK, Hill DL (2006) Age-related decrease of the 
chorda tympani nerve terminal field in the nucleus of the solitary tract is prevented by dietary sodium restriction during development. Neuroscience 137:1229-1236. CrossRef Medline

Spector AC, Glendinning JI (2009) Linking peripheral taste processes to behavior. Curr Opin Neurobiol 19:370-377. CrossRef Medline

Spector AC, Travers SP (2005) The representation of taste quality in the mammalian nervous system. Behav Cogn Neurosci Rev 4:143-191. CrossRef Medline

Spector AC, Guagliardo NA, St John SJ (1996) Amiloride disrupts $\mathrm{NaCl}$ versus $\mathrm{KCl}$ discrimination performance: implications for salt taste coding in rats. J Neurosci 16:8115-8122. Medline

Sun C, Dayal A, Hill DL (2015) Expanded terminal fields of gustatory nerves accompany embryonic BDNF overexpression in mouse oral epithelia. J Neurosci 35:409-421. CrossRef Medline

Sun C, Hummler E, Hill DL (2017) Selective deletion of sodium salt taste during development leads to expanded terminal fields of gustatory nerves in the adult mouse nucleus of the solitary tract. J Neurosci 37:660-672. CrossRef Medline
Trachtenberg JT, Chen BE, Knott GW, Feng G, Sanes JR, Welker E, Svoboda K (2002) Long-term in vivo imaging of experience-dependent synaptic plasticity in adult cortex. Nature 420:788-794. CrossRef Medline

Whitehead MC (1988) Neuronal architecture of the nucleus of the solitary tract in the hamster. J Comp Neurol 276:547-572. CrossRef Medline

Willott JF, Aitkin LM, McFadden SL (1993) Plasticity of auditory cortex associated with sensorineural hearing loss in adult C57BL/6J mice. J Comp Neurol 329:402-411. CrossRef Medline

Wong RO (1999) Retinal waves: stirring up a storm. Neuron 24:493-495. CrossRef Medline

Woolsey T (1990) Peripheral alteration and somatosensory development. In: Deevelopment of sensory systems in mammals (Coleman J, ed), pp 461-516. New York: Wiley.

Zheng S, Sun C, Hill D (2014) Postnatal reorganization of primary gustatory afferent terminal fields in the mouse brainstem is altered by prenatal dietary sodium history. Abstr Soc Neurosci. 